\title{
Evasão ou mobilidade: conceito e realidade em uma licenciatura*
}

\author{
Dropout or mobility: \\ the concept and the reality in a licentiate degree
}

\author{
Flaminio de Oliveira Rangel ${ }^{1}$. https://orcid.org/0000-0002-5033-5728 \\ Sergio Stoco ${ }^{1}$. https://orcid.org/0000-0001-6369-4466 \\ José Alves da Silva ${ }^{1}$. https://orcid.org/0000-0001-5597-8645 \\ Leonardo André Testoni ${ }^{1}$. https://orcid.org/0000-0001-9140-4788 \\ José Guilherme de Oliveira Brockington ${ }^{2}$. https://orcid.org/0000-0003-3033-0919 \\ Itale Luciane Cericato ${ }^{1}$. https://orcid.org/0000-0003-1163-3551
}

Resumo: Considerando a saída significativa de alunos no primeiro ano do curso de Licenciatura em Ciências da Universidade Federal de São Paulo e o cenário sócio-político da expansão do ensino superior no país, problematizamos o emprego do conceito de evasão para referir-se a essa saída prematura. Por meio de uma pesquisa-ação com a participação de alunos e de pesquisadores coletamos dados de 2011 a 2016 em questionários online e no diário de campo. Nossos resultados indicam ser necessário uma permanente precisão conceitual do termo evasão, na medida em que a saída antecipada de discentes não se configurou apenas com situações decorrentes do abandono do compromisso com os estudos devido ao insucesso escolar. Diferentemente do descrito em parte da literatura e nas ações institucionais em vários níveis, o discente altera, preventivamente, suas opções de estudo, considerando a mobilidade, as condições de precariedade e as pressões relativas ao trabalho.

Palavras-chave: Evasão escolar. Mobilidade escolar. Vulnerabilidade acadêmica. Condições socioeducacionais.

\begin{abstract}
Considering the significant dropout of students in the first year of the Sciences - Licentiate Degree of the Federal University of São Paulo and the socio-political scenario of the expansion of higher education in the country, we problematize the use of the concept of avoidance to refer to this premature exit. Through action research, with the participation of students and researchers, we collected data, from 2011 to 2016, in online questionnaires and field diaries. Our results indicate an inadequacy or a permanent need for conceptual precision in relation to the invariant "evasion" component, since the early departure of students was not only a result of the abandonment of the commitment to the studies due to school failure. Differently from what is described in part of the literature and in institutional actions at various levels, students, considering mobility, precarious conditions and work-related pressures, change their options of study preventively.
\end{abstract}

Keywords: School dropout. School mobility. Academic vulnerability. Socio-educational conditions.

\footnotetext{
*Aprovação no Comitê de Ética CEP n ${ }^{\circ}$ 1231/11, UNIFESP.

${ }^{1}$ Universidade Federal de São Paulo (UNIFESP), Departamento de Ciências Exatas e da Terra, Diadema, SP, Brasil. E-mail: flaminio.rangel@unifesp.br

${ }^{2}$ Universidade Federal do ABC (UFABC), Centro de Ciências Naturais e Humanas, Santo André, SP, Brasil.
} 
Rangel, F. O.; Stoco, S.; Silva, J. A.; Testoni, L. A.; Brockington, J. G. O., Cericato, I. L.

\section{Contexto e objetivos}

Neste trabalho, baseado em seis anos de atividades do Projeto Zero ${ }^{3}$, com resultados parciais discutidos no XIV Encontro de Pesquisa em Ensino de Física (RANGEL et al., 2012) e no X Encontro Nacional de Pesquisa em Ensino de Ciências (RANGEL et al., 2015), analisamos a adequação do conceito de evasão para referir-se à saída prematura de estudantes do curso de Licenciatura em Ciências da Universidade Federal de São Paulo (Unifesp), câmpus Diadema. Por ser um conceito importante na avaliação da qualidade e rendimento dos cursos, assim como dos gastos públicos, "no nível superior, a evasão se torna um problema tanto para os estudantes como para as instituições, pois pode representar a perda de qualificação do jovem brasileiro e, um problema ainda maior, desperdício de recursos públicos." (SANTOS; ARABI; CESPEDES, 2015, p. 2), pretendemos problematizar o emprego do conceito de evasão e investigar a componente invariante de um conceito (HARDY-VALLÉE, 2013), ou seja, as propriedades que não se alteram e são comuns a um determinado conjunto para refletir sobre sua adequação e aplicabilidade no contexto das licenciaturas em ciências, particularmente a partir da expansão do ensino superior

A exemplo do quadro nacional o curso é marcado, desde a sua criação em 2010, pelo Programa de Apoio a Planos de Reestruturação e Expansão das Universidades Federais (REUNI I) e pelo Sistema de Seleção Unificada (SISU). Estes programas, associados a outras políticas nacionais, possibilitaram importante aumento do acesso ao ensino superior de diferentes setores sociais, em especial os de menor renda. Possibilitaram, também, níveis mais avançados de mobilidade dos estudantes entre as universidades brasileiras. Por outro lado, ainda como marcas desses programas, o curso depara-se com a precarização universitária gerada por uma expansão com orçamentos insuficientes e pela falta de planejamento. Assim, novos setores sociais, após um esforço significativo, acessam a universidade pública federal e deparam-se com diversos processos de vulnerabilidade acadêmica ${ }^{4}$, por um lado, e com a pressão do mercado de trabalho para obterem um título, por outro.

Nas licenciaturas em que as ciências são elementos estruturantes vemos agravantes a esse quadro de vulnerabilidade: a trajetória de baixo desempenho do ensino básico revelado pelos dados do Programme for International Assessment (PISA, Programa Internacional para Avaliação de Alunos), a ausência de métodos ativos para o ensino de ciências, a negligência

\footnotetext{
${ }^{3}$ Nascido em 2011 de uma parceria entre docentes e discentes do Curso de Licenciatura em Ciências do câmpus Diadema da Unifesp e docentes do Laboratório Interdisciplinar de Pesquisa-Ação sobre Comunidade Saudável do Centro Multidisciplinar para Investigação Biológica (CEMIB) da Unicamp, o Projeto Zero cresceu e transformouse em 2014 num Programa de Ensino, Pesquisa e Extensão centrado no desafio de pesquisar e disponibilizar a construção de Letramentos Científicos Múltiplos, com ciência e tecnologia de ponta, às camadas mais vulneráveis da população, particularmente aos professores e alunos das escolas públicas do ensino básico, visando o seu empoderamento pelo conhecimento.

${ }^{4}$ Vulnerabilidade acadêmica: seguimos a definição do Plano Nacional de Assistência Estudantil (PNAES), que indica o conjunto de fatores socioeconômicos, culturais, psicológicos, familiares, cognitivos e institucionais que cria dificuldades para a permanência do discente no ambiente acadêmico e favorece a sua saída.
} 
quanto ao caráter interdisciplinar das formações científicas na construção curricular (PIAGET, 2002). O curso em questão nasce num contexto de globalização em que essas características são intensificadas e transformadas pelas mudanças socioeconômicas, com repercussões políticas e culturais significativas para a sociedade, a denominada Nova Gestão Pública.

A Nova Gestão Pública (New Public Management) se apresenta sempre com uma proposta de reorganização do setor público, de modo a melhorar controles e eficiência, o que implica uma consequente ação de responsabilização. "Dependendo do contexto ela intenciona contrariar a agenda da Nova Direita de privatização e gerencialismo e, em outros países, como o primeiro passo para a realização dessa agenda” (HOOD, 1995, p. 107).

No Brasil, um dos seus aspectos reflete-se no aprofundamento da proletarização e da alienação no trabalho dos professores do ensino básico brasileiro delineando um cenário "entre a dilapidação moral e a missão redentorista" (COSTA; FERNANDES NETO; SOUZA, 2009 , p. 59). O que reflete diretamente nas expectativas que jovens licenciandos têm sobre sua futura carreira.

O surgimento das redes digitais de comunicação (CASTELS, 2006) trouxe novas relações na produção em geral e, particularmente, na produção do conhecimento. A imersão dos estudantes num oceano digital de informações que reconfiguram, em tempo real, as fronteiras entre o real e o virtual, associada às questões de empregabilidade e de perspectiva social para a juventude, produz novas condições e contextos de produção do conhecimento (VALENTE, 1999) que as novas metodologias e recursos de formação de educadores (ALMEIDA, 2004) tentam dar conta, apesar do seu ainda pequeno impacto na formação inicial.

Em meio a todas essas mudanças, a mobilidade acadêmica emerge simultaneamente como um elemento de inclusão e de democratização do ensino que beneficiaria a formação do aluno e, também, como elemento presente na flexibilização e na reorientação da divisão territorial do trabalho (SANTOS, 1996) em consonância com os interesses do grande capital e frequentemente dissonante com os interesses de desenvolvimento nacional. Neste sentido, é preciso compreender a mobilidade acadêmica e o consequente fluxo nacional de alunos como parte de um processo em que mais especialização do trabalho, regionalmente localizado, leva a mais movimento (mobilidade), que por sua vez gera novas especializações, em um movimento circular (SANTOS, 1996). Desta forma, novos elementos de vulnerabilidade são gerados perante o aluno que se vê inserido num processo de flexibilização das condições e das relações de trabalho.

Em 1995 foi criada a Comissão Especial de Estudos sobre a Evasão nas Universidades Brasileiras, do Ministério da Educação, que promoveu um estudo com parte significativa das Instituições Federais de Ensino Superior (IFES) brasileiras, tendo como elemento motivador a preocupação do então titular da Secretaria da Educação Superior (SESU), com a diferença entre matriculados e concluintes no ensino superior brasileiro, por ele denominada evasão (BRASIL, 1996).

Como revelado no próprio documento, quando se considera a diferença entre matriculados e concluintes, as taxas são elevadas em quase todo o mundo (exemplos dos EUA, Argentina e Europa), sendo bastante reduzida quando se considera como evasão apenas aqueles que deixaram de frequentar o ensino superior (não se matricularam em outro curso ou instituição).

Não por outra razão o estudo reconhece que a "evasão de estudantes é fenômeno complexo e comum às instituições universitárias no mundo contemporâneo" (BRASIL, 1996, p. 18), transparecendo em "suas dimensões concretas: evasão de curso, evasão da instituição e 
evasão do sistema de ensino superior" (BRASIL, 1996, p. 13). Devido a limitação de tempo e condições, o grupo decidiu deter-se apenas na evasão de curso (com o intuito de pensar melhorias que pudessem ser implementadas) deixando de lado, como argumentamos aqui, uma parte significativa do processo que está relacionada à mobilidade dos estudantes e, portanto, mantendo a conotação do termo evasão com o chamado fracasso escolar.

A evasão, como denominação de um processo de fracasso escolar, remonta ao próprio processo de institucionalização da forma escolar e da massificação no atendimento do ensino no Brasil, nas primeiras décadas do século XX, de forma que a historicidade do conceito, no que se refere à educação básica, vai das preocupações com relação ao abandono no primeiro ciclo da educação primária e à formulação da promoção automática com Anísio Teixeira e Dante Moreira Leite nos anos 1950 (REVISTA BRASILEIRA DE ESTUDOS PEDAGÓGICOS, 2003-2017), com a preocupação a respeito do estigma da reprovação (PATTO, 2000), até a discussão sobre os fluxos escolares, a ponto de se pensar em uma pedagogia da repetência (RIBEIRO, 1991).

Cabe notar que, no Instituto Nacional de Estudos e Pesquisas Educacionais Anísio Teixeira (Inep), para categorizar empiricamente os conceitos, define-se que a taxa de evasão é a porcentagem de alunos matriculados numa determinada série ou nível de ensino, num determinado ano letivo, que não estão matriculados em nenhuma série no ano letivo seguinte; já a taxa de abandono é a taxa de alunos que abandonam o curso ao término do ano letivo. Interessante notar que esta categorização é utilizada para as informações da educação básica (censo escolar) e para educação superior (censo da educação superior) e que o mesmo cuidado (só caracterizar evasão quando o aluno sai do sistema escolar) não é atendido em muitos textos que tratam do tema.

Toda essa discussão sobre o abandono / evasão está circunscrita ao fenômeno da Educação Básica. Esta, por mais que contenha sempre os mesmos elementos da tomada de decisão de deixar de frequentar o curso escolar (aqui definida como vulnerabilidade acadêmica) e não ignorando a possibilidade da decisão da evasão ser motivada por cálculos racionais (por mais que acreditemos que a frequência à escola representa um ganho de cidadania e desenvolvimento humano, nem sempre a realidade material garante esta possibilidade potencial, gerando uma descrença no sistema) ainda assim está referida, majoritariamente, a pessoas (crianças e adolescentes) que estão submetidas à compulsoriedade do ensino escolar (obrigatório e direito público subjetivo dos 4 aos 17 anos de idade) e, portanto, não permite equiparação ao conceito de evasão quando trata-se do ensino superior. O que exige uma ressignificação ou precisão teórico-conceitual.

Entre as dificuldades para precisar o conceito de evasão e sua observação empírica, particularmente em seu elemento invariante (HARDY-VALLÉE, 2013) está a forma de registro de acompanhamento dos alunos. $\mathrm{Na}$ Educação Básica o censo escolar possui um registro identificador do aluno que permite acompanhar sua trajetória independentemente da situação administrativa (pública, privada, em diferentes localidades do país etc.). Já na educação superior o registro é realizado, frequentemente, por instituição, o que dificulta o acompanhamento da trajetória do aluno bem como a categorização empírica de abandono e evasão, conforme define o INEP.

É comum encontrarmos na literatura autores que como Baggi e Lopes (2011) e Silva Filho et al. (2007) vinculam a evasão no ensino superior da mesma forma com que é vinculada no ensino básico: ao insucesso escolar e ao consequente abandono dos estudos. Os autores 
consideraram como parâmetro alunos matriculados que não se matriculam no ano posterior ou matriculados que não se diplomam. As fronteiras do curso local são as que definem os limites da evasão, sem, no entanto, conferirem que muitos ingressantes podem ser evadidos de outros cursos. No relatório da comissão entregue ao MEC, Ristoff $(1995$, p. 19) já alertava que

\begin{abstract}
Parcela significativa do que chamamos evasão, no entanto, não é exclusão, mas mobilidade, não é fuga, mas busca, não é desperdício mas investimento, não é fracasso - nem do aluno nem do professor, nem do curso ou da instituição - mas tentativa de buscar o sucesso ou a felicidade, aproveitando as revelações que o processo natural do crescimento dos indivíduos faz sobre suas reais potencialidades.
\end{abstract}

Assim, a evasão, outrora compreendida como abandono de curso por dificuldades de toda ordem, pode ser complexificada em todas as suas nuances levando-se em conta, por exemplo, o fluxo nacional de alunos engendrado por essas transformações.

Na problemática da evasão em licenciaturas, particularmente as que envolvem ciências da natureza, a literatura acrescenta a desvalorização social da carreira docente, a baixa remuneração, as condições precárias de trabalho, a incompreensão do perfil dos licenciandos por parte das universidades e as inadequações curriculares como elementos que favorecem a saída de alunos (GATTI et al., 2009). Embora programas como o Programa Nacional de Assistência Estudantil (PNAES) contemplem os aspectos socioeconômicos, outros fatores são analisados separadamente pela literatura, porém não como um processo global, multifatorial, que induz o aluno a mudar de curso ou até mesmo a abandonar os estudos. Ressalta-se que, no Censo da Educação Superior, conforme dados divulgados pelo INEP (2018), Tabela 1, a taxa de estudantes cursando, em relação ao total de matrículas no ensino superior, é decrescente, enquanto que a taxa de alunos não cursantes (matrículas trancadas + matrículas desvinculadas) é crescente, conforme indica a Figura 1.

Tabela 1. Evolução das matrículas (matriculados, matrícula trancada, matrícula desvinculada do curso) nos cursos de graduação presenciais e à distância das IES, 2011-2016

\begin{tabular}{cccccc}
\hline Ano & $\begin{array}{c}\text { Total matrículas } \\
\text { no ensino superior }\end{array}$ & $\begin{array}{c}\text { Matriculados } \\
\text { e cursando }\end{array}$ & $\begin{array}{c}\text { Matrículas trancadas } \\
\text { + desvinculadas }\end{array}$ & $\begin{array}{c}\text { Matrículas } \\
\text { trancadas }\end{array}$ & $\begin{array}{c}\text { Matrículas } \\
\text { desvinculadas }\end{array}$ \\
\hline 2011 & 8.922 .950 & 6.739 .689 & 2.079 .144 & 755.997 & 1.323 .147 \\
2012 & 9.532 .085 & 7.037 .688 & 2.399 .347 & 967.595 & 1.431 .752 \\
2013 & 9.904 .051 & 7.305 .977 & 2.500 .755 & 1.035 .463 & 1.465 .292 \\
2014 & 10.771 .950 & 7.828 .013 & 2.834 .096 & 1.208 .961 & 1.625 .135 \\
2015 & 11.174 .282 & 8.027 .297 & 3.035 .956 & 1.300 .410 & 1.735 .546 \\
2016 & 11.440 .726 & 8.048 .701 & 3.284 .647 & 1.254 .960 & 2.029 .687 \\
\hline
\end{tabular}

Fonte: INEP (2018). 
Rangel, F. O.; Stoco, S.; Silva, J. A.; Testoni, L. A.; Brockington, J. G. O., Cericato, I. L.

Figura 1. Matrículas no ensino superior

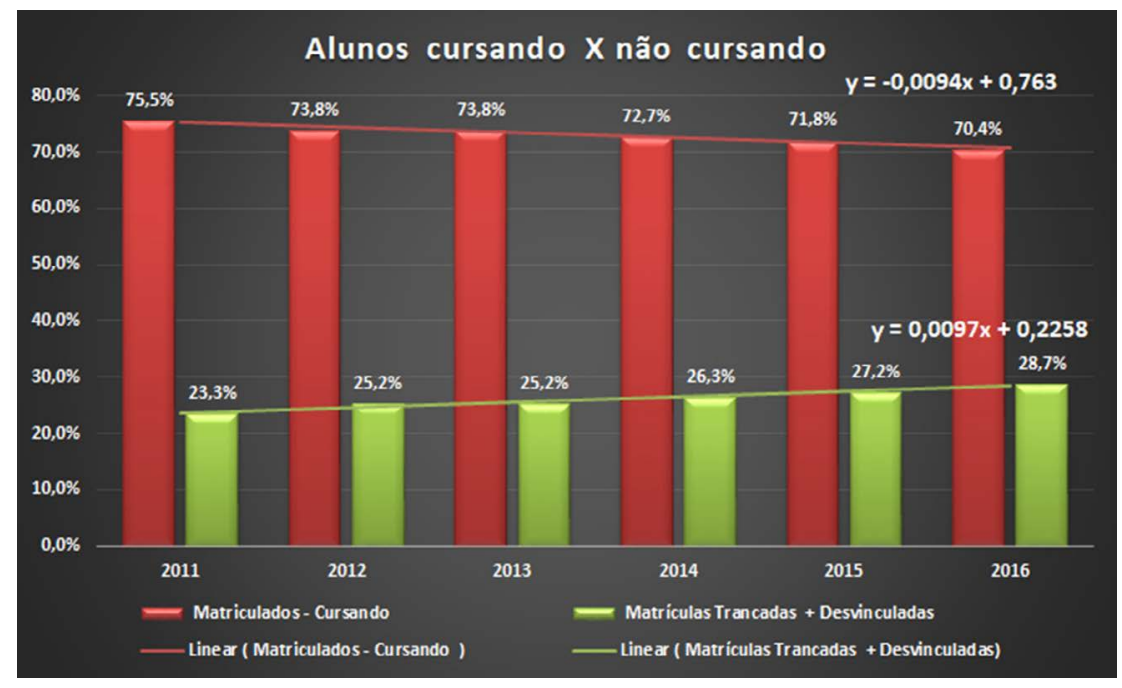

Fonte: elaborado pelos autores.

São indícios de que fatores relacionados às políticas nacionais para o ensino superior, associados a elementos de vulnerabilidade do aluno, impulsionam essa taxa crescente de não cursantes que, em tese, pode conter elementos de efetiva evasão da rede de ensino superior, mas, também, elementos de mobilidade acadêmica entre as universidades da rede pública ou privada, quer seja na forma de transferência ou simplesmente abandono, e nova entrada na rede, facilitada pela existência do Exame Nacional do Ensino Médio (ENEM), do SISU e do Fundo de Financiamento Estudantil (FIES) ${ }^{5}$.

A comprovação desta hipótese, em âmbito nacional, exigiria uma ampla e demorada pesquisa, com diversas instituições envolvidas, assim como uma eficaz metodologia de registro dos alunos que possibilitasse acompanhá-lo pelas diversas instituições. No presente trabalho, focaremos apenas como isso pode estar ocorrendo no curso de Licenciatura em Ciências da Unifesp, no qual a evasão e a vulnerabilidade aparecem associadas a uma questão curricular mais ampla decorrente do projeto pedagógico do curso (UNIVERSIDADE FEDERAL DE SÃO PAULO, 2019): como transformar alunos provenientes de uma cultura escolar de analfabetismo científico em educadores em ciências capazes de promover a literacia cientifica ${ }^{6}$ (CARVALHO, 2009) de seus alunos, num contexto de vulnerabilidade e de mobilidade? Esta questão torna-se ainda mais importante na medida em que o curso tem uma única entrada pelo SISU, porém tem quatro saídas com formações específicas: Física, Química, Biologia, Matemática. Os 100

\footnotetext{
${ }^{5}$ Programa do Ministério da Educação destinado a financiar a graduação de estudantes matriculados em instituições não gratuitas de ensino superior.

${ }^{6}$ Termo introduzido na educação em ciência por Paul Hurd em 1958. Surge com os sinônimos alfabetização científica, compreensão pública da ciência e cultura científica.
} 
alunos ingressantes no vespertino e os 100 no noturno cursam dois anos no ciclo básico e, posteriormente, seguem por mais dois anos com uma formação específica na área escolhida, acrescida com os estágios supervisionados, as práticas de ensino, as integrações das ciências e o trabalho de conclusão de curso. Além disso, o curso pertence ao campus Diadema, criado também pelo Reuni, o qual apresenta elementos gritantes de ausência de infraestrutura predial, de recursos humanos, para pesquisa etc., além de ficar em um município da Grande São Paulo altamente adensado, com alto grau de violência, sem tradição universitária local.

\section{Aspectos metodológicos}

A imersão de discentes e pesquisadores do curso num ambiente investigativo, permeado pela aprendizagem das ciências e pela pesquisa sobre o processo de formação inicial de professores vivenciado no curso, surge como característica marcante do presente trabalho. Neste sentido, esta pesquisa referenciou-se na proposta curricular do curso que considera o ato de pesquisar como recurso de ensino e, ao mesmo tempo, como objetivo formativo para o desenvolvimento da ação docente e buscou contribuir para a formação de professores-pesquisadores, nos moldes que propõe André (2010).

Estabelecendo o Curso de Licenciatura em Ciências da Unifesp como campo de pesquisa, partimos da sua localização no contexto do Programa de Apoio a Planos de reestruturação e Expansão das Universidades Federais, já que sua criação se deveu aos planos de expansão do ensino superior. Consideramos, também, as possíveis inter-relações entre Ciência, Tecnologia, Sociedade e Ambiente (SANTOS, 1999) vivenciadas nas trajetórias escolares dos alunos, que poderiam contribuir, positiva ou negativamente, com a evasão/mobilidade estudantil. Consideramos, ainda, nosso objetivo de entender e transformar a realidade do curso por meio da pesquisa e da intervenção, referenciada nessa pesquisa, dos alunos e pesquisadores inseridos nesse processo. Por isso, nos orientamos metodologicamente por uma pesquisa qualitativa em educação, norteada pela pesquisa-ação (PIMENTA; FRANCO, 2008, 2014; THIOLLENT, 2002) e com as seguintes características:

1. Explícita e significativa interação entre alunos, docentes e pesquisadores do curso, buscando dar prioridade aos problemas de pesquisa. A partir de um grupo de 13 alunos de iniciação científica e da sua interação com o restante dos alunos do curso, elaborou-se um questionário online, com 45 questões de múltipla escolha, sobre as condições socioeconômicas, a formação na escola básica e a relação com o curso. O questionário foi submetido aos alunos ingressantes das turmas de 2010 e 2011 e seus dados foram plotados em gráficos para que as tendências envolvidas na saída ou na permanência dos alunos no curso pudessem se revelar. Os questionários e seus resultados prévios foram discutidos pela equipe de pesquisadores do projeto para validação, contando com a colaboração de docentes da Comissão de Curso e do Núcleo Docente Estruturante (NDE). Após ajustes em algumas perguntas e eliminação de outras, o questionário foi submetido a uma nova validação perante uma equipe de pesquisadores em educação de diversos campi da universidade envolvidos com o Projeto Prodocência da Coordenação de Aperfeiçoamento de Pessoal de Nível Superior (CAPES). Desta forma, nossas análises se basearam nas 30 questões que permaneceram inalteradas após esse processo de validação, sendo que os dados coletados se referiam às turmas de ingressantes de $2010 \mathrm{a}$ 
2016. Baseamo-nos também nas anotações dos diários de campo e nos dados institucionais da Pró-Reitoria de Graduação e do Núcleo de Assistência Estudantil. Embora os gráficos revelassem porcentagens, a leitura deles sempre esteve voltada para uma interpretação qualitativa que revelasse os fatores presentes e as possíveis interrelações e proporções entre eles

2. Registro e acompanhamento das atividades de pesquisa e das decisões dos segmentos envolvidos no curso, como a Comissão de Curso, o NDE, o centro acadêmico e o próprio grupo de pesquisa. As observações e o registro foram realizados por meio de um Diário de Campo, um arquivo digital onde eram anotadas todas as ocorrências e observações consideradas relevantes pelo grupo, do dia a dia de pesquisa. As pressões familiares, as angústias pessoais, as dificuldades específicas com determinados conhecimentos, os desejos relativos à formação e à vida profissional, os planos pessoais em relação à universidade, as preocupações com as decisões do curso eram temas que se revelavam no diário de campo. Vários depoimentos apontavam o Curso de Licenciatura em Ciências apenas como um meio de entrar na universidade, uma forma propedêutica de capacitação para objetivos acadêmicos mais audazes, o que reforça nossa preocupação com o conceito utilizado de evasão.

3. O problema de pesquisa, a evasão, analisado a partir da saída de alunos no primeiro ano de curso - foi eleito por consenso a partir das preocupações de alunos, pesquisadores, Comissão de Curso, NDE, Secretaria Acadêmica, devido à significativa saída de alunos do curso nos dois primeiros semestres.

Nos dados coletados pelos questionários online, nas reuniões da Comissão de Curso e do NDE, nas reuniões do grupo de pesquisa, nas anotações do diário de campo, assim como nos controles institucionais de matrícula, os destaques emergentes foram: a saída significativa de discentes nos dois primeiros semestres do curso, em muitos casos previamente às avaliações; a porcentagem de discentes que desconheciam totalmente partes importantes do currículo do ensino médio; a presença expressiva de alunos de faixa etária mais elevada; alunos que não cursaram o ensino médio regular (educação de jovens e adultos, supletivo ou aqueles aprovados pelo ENEM); a predominância do pensamento baseado no senso comum, particularmente no que se refere às explicações e modos de agir das ciências.

\section{Resultados e conclusões}

Levantamentos preparatórios de 2010 e 2011 apontaram que as taxas de saída no primeiro ano de curso oscilavam em torno de $55 \%$, confirmadas posteriormente por novos levantamentos e por dados institucionais (SANTOS; ARABI; CESPEDES, 2015). Nos questionários para alunos ingressantes, taxas equivalentes correspondiam a alunos que, apesar do sucesso escolar (em oposição à ideia de fracasso escolar), de terem conquistado uma vaga na rede pública de ensino superior, declaravam que não tinham a pretensão de cursar Licenciatura em Ciências. Do ponto de vista institucional, a Comissão de Curso, em face da saída efetiva de alunos da sala de aula, via-se ano a ano perante a tarefa de reduzir as quatro turmas de 50 alunos cada uma ( 2 no noturno e 2 no vespertino) a duas turmas, uma em cada período. A partir desses primeiros apontamentos, levantamos dados sobre esse fenômeno entre 2010 e 2016, compondo a série de dados da Tabela 2, visando não a quantificação da evasão, mas entender 
a dinâmica e os fatores que geravam o fenômeno. O questionário online aplicado aos alunos ingressantes apontou taxas entre 44,2\% (2016) e 63\% (2012) dos alunos que entram no curso por opção, prioritária ou secundária, mas revelou também taxas entre 37\% (2012) e 55,8\% (2016) de estudantes que irão decidir se permanecem ou não durante o curso, podendo, pela mobilidade, por um novo ENEM ou simplesmente optando pela rede particular, migrar para outros cursos ou universidades. Entre os ingressantes, taxas entre 20\% (2011) e 34,9\% (2016) eram oriundos de outras universidades, sem terem completado o curso. Os ingressantes que já tinham formação superior variavam entre 0\% (2015) a $20 \%$ (2012). Os dados apontam para a existência de um setor dos discentes que permanece sem uma opção profissional constituída e que entrou para a licenciatura em ciências pela classificação que lhes coube no SISU, mas não necessariamente por identificação com carreira de professor.

Tabela 2. Amostragem 2010-2016

\begin{tabular}{lrrrrrrr}
\hline & $\mathbf{2 0 1 0}$ & $\mathbf{2 0 1 1}$ & $\mathbf{2 0 1 2}$ & $\mathbf{2 0 1 3}$ & $\mathbf{2 0 1 4}$ & $\mathbf{2 0 1 5}$ & \multicolumn{2}{c}{$\mathbf{2 0 1 6}$} \\
\hline Formulários enviados & 36 & 108 & 168 & 114 & 204 & 24 & 180 \\
Respostas & 14 & 54 & 116 & 32 & 73 & 5 & 43 \\
Porcentagem & $39 \%$ & $50 \%$ & $69 \%$ & $28 \%$ & $36 \%$ & $21 \%$ & $24 \%$ \\
\hline
\end{tabular}

Fonte: elaborada pelos autores.

A taxa de alunos oriundos da rede particular oscilou de $46 \%$ a $35 \%$, enquanto os oriundos de rede pública e dos cursos supletivos ou normais oscilaram de $80 \%$ e $54 \%$, conforme a Figura 2. Estes dados mostram nuances escolares do perfil socioeconômico dos alunos do Curso de Ciências registrado em 2015 pela Pró-Reitoria de Graduação:

Figura 2. Ingressantes 2010-2016

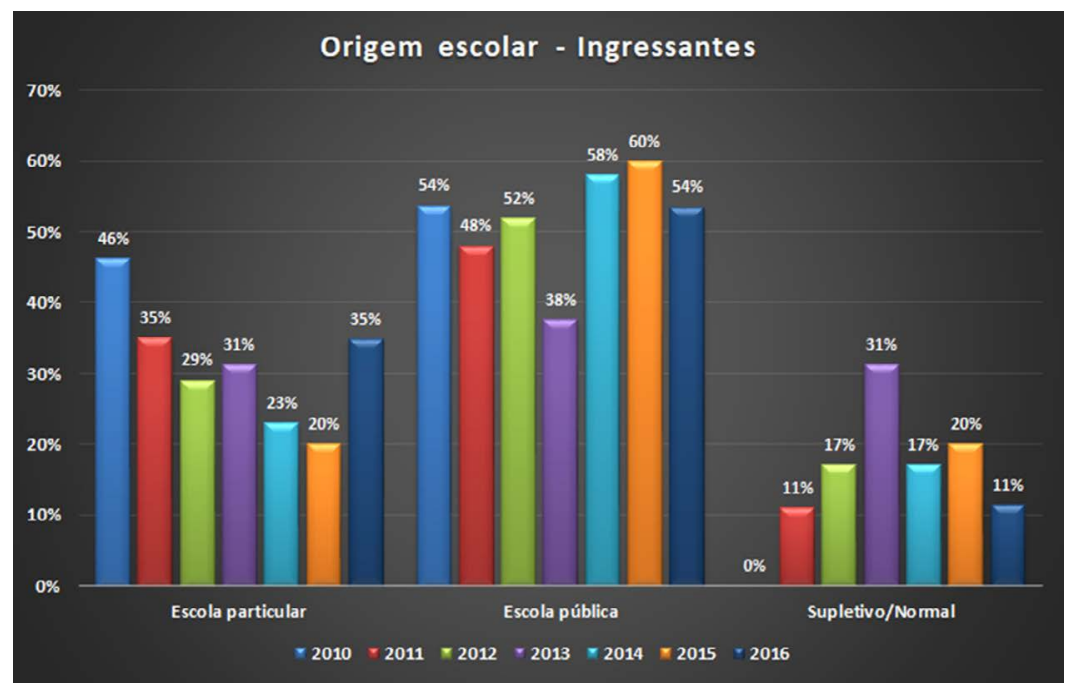

Fonte: elaborada pelos autores. 
O campus sediado no ABCD é dos que apresenta maior diversidade de perfil de ingressantes por carreira escolhida no que toca a renda familiar. [...] A mediana de renda do curso de Ciencias-Licenciatura noturno fica entre três e quatro salários mínimos, enquanto a de Engenharia Quimica integral está próxima de dez salários mínimos. Nos demais cursos de graduação, o padrão geral e de medianas entre quatro e seis salários mínimos. (UNIVERSIDADE FEDERAL DE SÃO PAULO, 2016, p. 63).

Essa diversidade no perfil socioeconômico do campus apresenta-se na Licenciatura em Ciências por ser o curso da Unifesp com a maior diferença entre a maior e a menor nota de entrada pelo SISU, no período 2010-20147 , sendo a maior discrepância no período noturno. (Figura 3).

Figura 3. Maior e menor nota no SISU

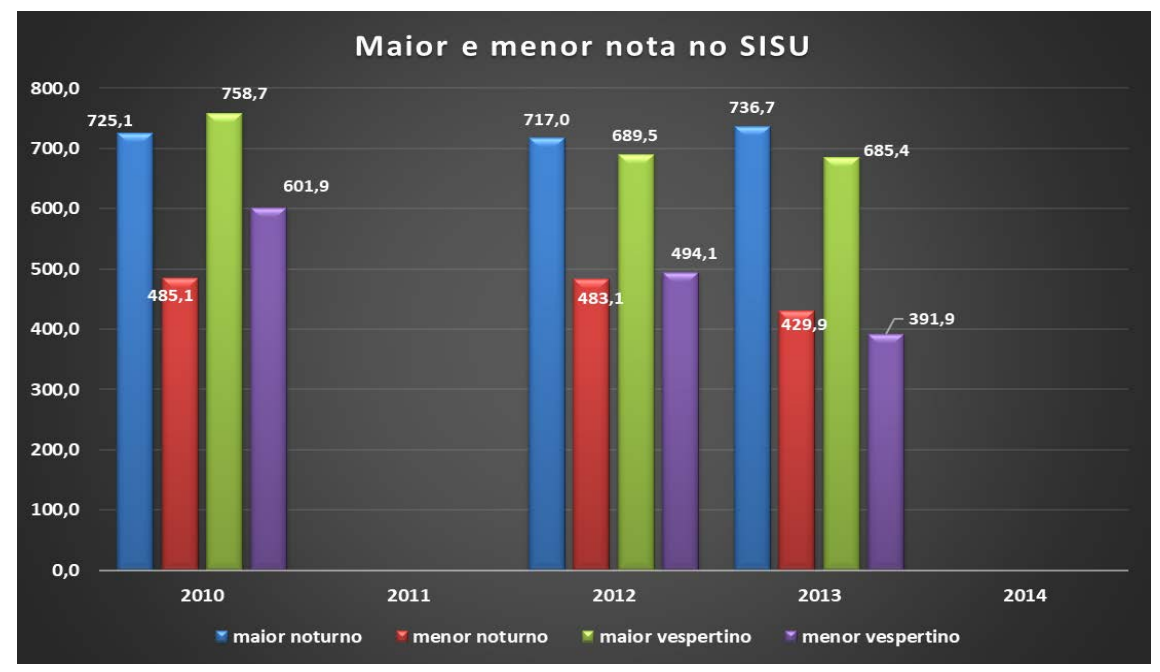

Fonte: elaborada pelos autores.

Os alunos oriundos dos extratos sociais menos favorecidos, geralmente formados na escola pública, nos supletivos e nas antigas escolas normais vivenciam de forma mais acentuada, a partir do ingresso na universidade, um conjunto de elementos de vulnerabilidade, desde os de natureza socioeconômica até os de ordem emocional ou de linguagem. As deficiências na formação, a falta de hábito de estudos e de identidade profissional, embora também contribuam significativamente para a vulnerabilidade desses setores, aparecem como elementos comuns entre o conjunto dos estudantes. As anotações do diário de campo revelaram que, particularmente para

\footnotetext{
${ }^{7}$ Dados fornecidos pelos relatórios da Pró-Reitoria de Graduação. Nos anos de 2011 e 2013 não havia dados das notas máximas e mínimas de cada curso.
} 
as mulheres, havia uma incompreensão em relação ao estudo universitário por parte do núcleo familiar, e uma forte pressão no sentido do seu abandono e busca de emprego para ajudar na sustentação financeira da família. Outros casos registrados apontavam que, para alguns alunos que trabalhavam e moravam bem distante do campus, o custo de manutenção na universidade pública, com comida e transporte, era maior do que se ele estudasse numa universidade particular perto de sua residência ou local de trabalho.

Alunos que se constituem como primeiro membro da família a cursar o ensino superior aparecem como um fenômeno bastante significativo no curso, conforme aponta a Figura 4. Esses dados concretizam as políticas de expansão universitária e de inclusão de novos setores sociais no ensino superior que trazem um perfil ainda pouco conhecido da academia. Além disso, o distanciamento e o desconhecimento da cultura universitária por parte dos setores socialmente mais vulneráveis, e o modelo abstrato de aluno, com traços universalizantes e ahistóricos com que a universidade constuma trabalhar, são fatores que dificultam a transposição das barreiras entre o senso comum e o conhecimento acadêmico. Registra-se, desta forma, outro elemento de vulnerabilidade no diário de campo. Significativas dificuldades com a linguagem dos livros e do professor, desconhecimento de vários conceitos ou de contextos científicos, particularmente de matemática e ciências relativos ao ensino fundamental II e médio, incompreensão dos fluxos e dinâmicas da universidade, dificuldades com o raciocínio lógico-científico, também surgiram nos registros do diário de campo. Essas dificuldades mostraram-se consistentes com o levantamento de que taxas entre 8\% e 13\% dos ingressantes entre 2011 e 2014 não haviam tido os conteúdos de Física no ensino médio, por falta de professor na rede pública ou pelo substituto ser de outra área ou pelo professor faltar exessivamente. Em Química, as taxas variavam entre $5 \%$ e $9 \%$, Biologia entre 4\% e 13\% e Matemática entre $0 \%$ e $4 \%$.

Figura 4. Cultura universitária

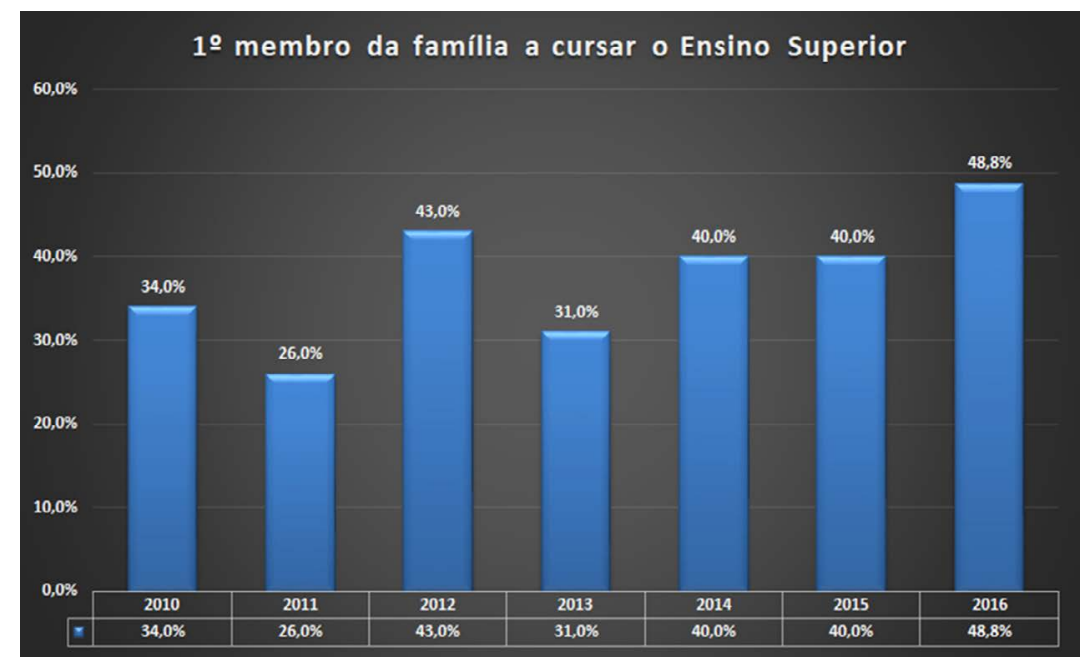

Fonte: elaborada pelos autores. 
As avaliações em Física I revelam que parcela importante de ingressantes apresenta dificuldades ou desinteresse com o conteúdo que lhes é apresentado, o que leva a porcentagens significativas de ausência nas avaliações P1 e P2, culminando com taxas também expressivas de reprovação por falta $(\mathrm{RF})(>25 \%)$ ou mesmo por nota $(\mathrm{RN})$, conforme apontam os dados da figura 5.

Figura 5. Avaliações em Física I

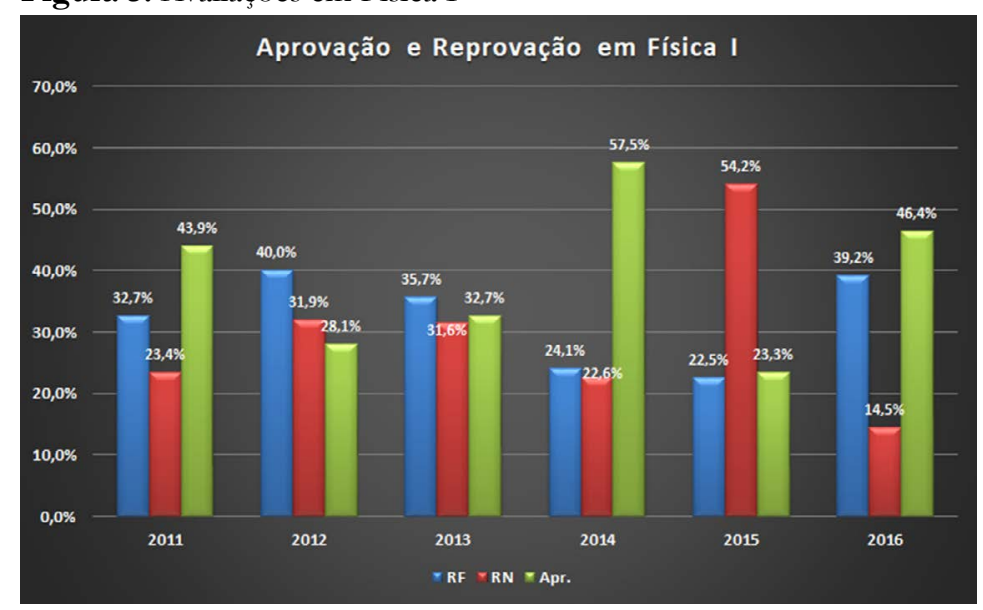

Fonte: elaborada pelos autores.

De 2011 a 2016, taxas entre 31\% e 53\% correspondem a ingressantes que vieram de outros cursos ou universidades. Taxas entre $9 \%$ e $25 \%$ correspondiam a discentes já formados e que estavam no curso para uma segunda formação. Taxas entre 17\% e 32\% correspondem aos que estavam sem estudar há mais de cinco anos. A associação de taxas de evadidos de outros cursos próximas às taxas de evasão, taxas significativas de pessoas que voltam aos estudos, quer seja para a primeira ou segunda formação, configura-se como um forte indicativo de um movimento de mobilidade dos estudantes pela rede de ensino superior e não apenas a evasão provocada pelo insucesso escolar, com o consequente abandono dos estudos.

O levantamento de ausências nas avaliações, P1 e P2, de Física 1, uma unidade curricular obrigatória para ingressantes, conforme figura 6, aponta taxas entre $25 \%$ e $68,3 \%$ de alunos ausentes, mesmo sabendo-se que, em caso de reprovação, a estrutura curricular não impede a evolução no curso devido à inexistência de pré-requisitos. Situação semelhante ocorre em Matemática 1, indicando que, em muitos casos, a saída do curso não se motiva, como prevê o conceito de evasão, devido ao insucesso escolar, configurado por sucessivas reprovações.

Se tomarmos como referência as formações superiores nas áreas de saúde e de engenharia, que além do período integral dos cursos demandam mais horas de estudos em casa, nossos dados apontam para uma cultura de pouco estudo. Entre $72 \%$ e $84 \%$ dos alunos estudam menos de duas horas diárias, fora do horário de aula, num curso de apenas um período (Figura 7), sendo que parte desse tempo é dedicada a atividades a serem entregues e os relatos apontam para um baixo nível de leitura do livro didático. Registros no diário de campo revelam que parcela dos alunos vivenciou uma progressão escolar pouco dependente do esforço 
ou do estudo do aluno. Outros relatos apontam que, em alguns casos, a certificação na escola básica, apesar da ausência de sistemática de professores, particularmente de Física, Química ou Biologia, e, consequentemente, a ausência de partes significativas do programa dessas áreas, fornece argumentos para o pouco estudo, para a progressão automática e responsabilização da instituição pelas falhas.

Figura 6. Ausência nas avaliações P1 e P2 de Física I

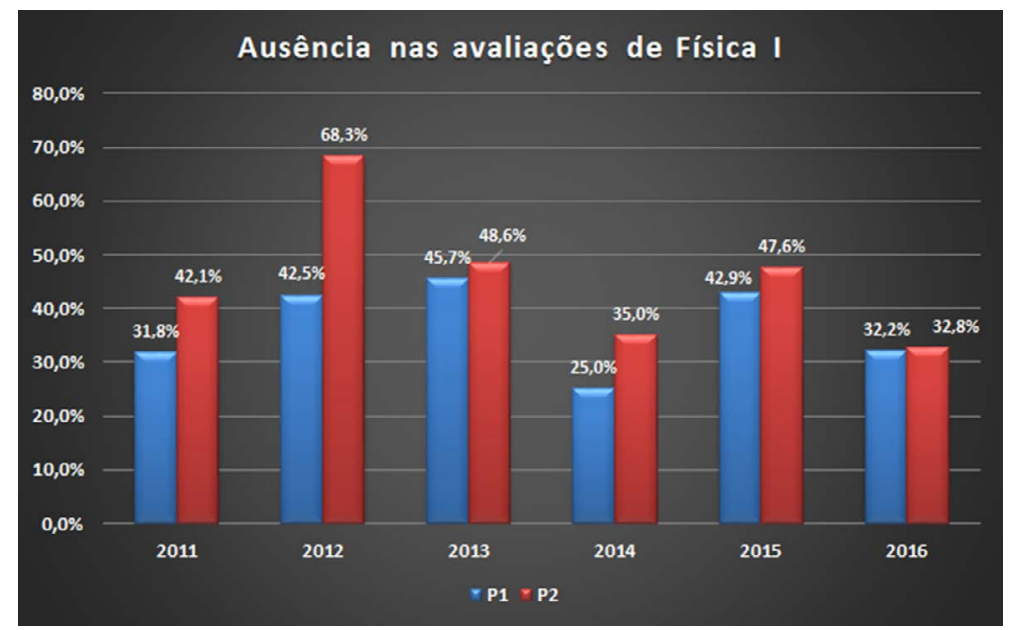

Fonte: elaborada pelos autores.

Figura 7. Tempo de estudo

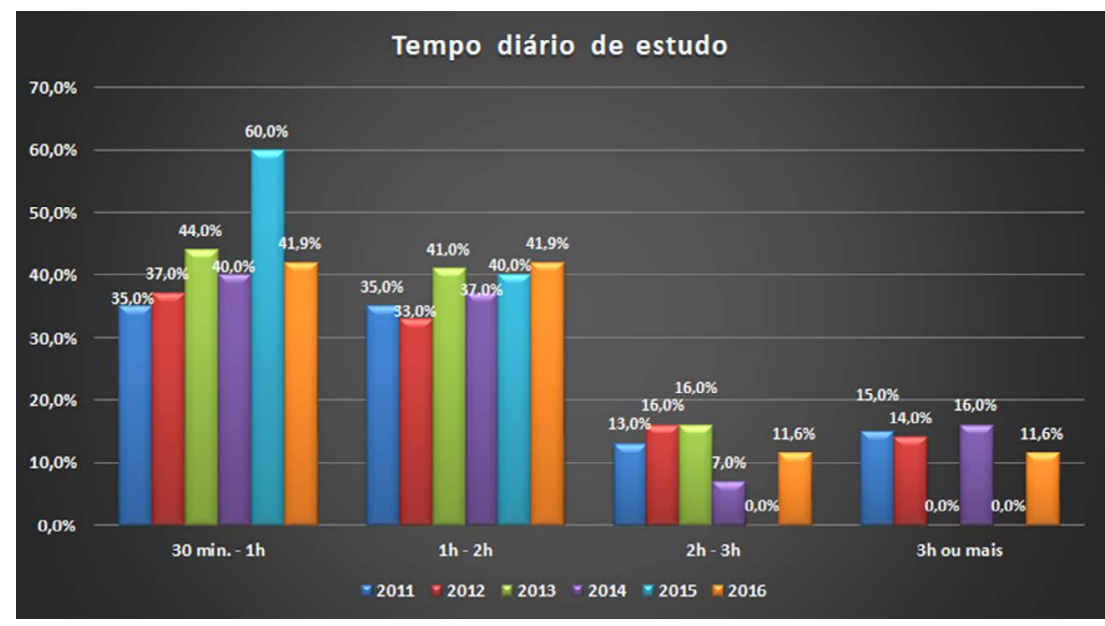

Fonte: elaborada pelos autores. 
Como fator agravante e associado à cultura de pouco estudo, os dados revelaram que taxas em torno de $40 \%$ dos alunos gastam mais de três horas diárias no transporte de ida e volta à universidade. A fragilidade da estrutura universitária com restaurantes, moradias, laboratórios, bibliotecas, salas de aula, recursos tecnológicos e culturais, muito aquém do necessário, aumenta as dificuldades dos alunos quando estão no campus. Desta forma, as precariedades de infraestrutura acadêmica, as condições de transporte e alimentação, dificultam a superação da cultura do pouco estudo e atuam como freio à construção de uma cultura acadêmico-científica.

Por fim, para completar a discussão sobre os elementos de vulnerabilidade, concordamos com os dados e análises de Colagrande, Rangel e Leite (2013), relativos às crenças dos alunos do mesmo curso sobre a natureza das ciências e as relações Ciência, Tecnologia, Sociedade e Ambiente (CTSA). Os resultados apontaram que 35\% dos 139 alunos entrevistados não tiveram contato com debates sobre a natureza do conhecimento científico ou sobre a relação ciência, tecnologia, sociedade e ambiente durante o período escolar e $48 \%$ tiveram poucas vezes. Embora as concepções curriculares do curso considerem a Ciência enquanto um processo sócio-histórico, de produção social do conhecimento, verificou-se que $69 \%$ dos entrevistados apresentaram concepções ingênuas (RUBBA; HARKNESS, 1993). Essas concepções ingênuas, associadas às dificuldades com o raciocínio lógico-matemático ou com o raciocínio causal baseado em evidências, muito provavelmente herdadas da educação básica, indicam que a compreensão do ambiente universitário e científico do curso fica distorcida e se transforma em um elemento que retroalimenta as dificuldades com a linguagem e com a aprendizagem dos conceitos científicos no contexto do curso.

Embora não tenhamos investigado especificamente as relações afetivas entre os alunos e entre eles e os diversos segmentos do curso, obtivemos registros no diário de campo que apontavam a formação de grupos de alunos adolescentes que se organizavam em torno a alunos mais velhos, mais maduros e com a relações familiares e de trabalhos mais estáveis e consolidadas. Nestes grupos, as referências à vivência profissional e à superação das dificuldades emocionais nos contextos acadêmico, familiar e profissional eram elementos importantes do convívio entre eles. Ribeiro e Higa (2015) apontam que bons laços afetivos e uma boa orientação vocacional podem ser formas de atenuar as demandas e dificuldades dos alunos ao adentrarem no mundo universitário.

Apesar de todos esses elementos de vulnerabilidade, os dados institucionais levantados pelo Núcleo de Apoio ao Estudante (NAE) ${ }^{8}$ entre 2010 e 2011 indicavam que 48\% dos alunos entrevistados, quando solicitam desligamento, pretendiam mudar de curso ou de universidade; $11 \%$ conseguiram bolsa do Programa Universidade para Todos (PROUNI) ${ }^{9}$ e 6,5\% pretendiam fazer outro curso dentro da própria Unifesp. Desta forma, taxas em torno de $70 \%$ declaravam, portanto, que continuariam os estudos.

${ }^{8}$ Criado sob a orientação do Programa Nacional de Assistência Estudantil (PNAES).

${ }^{9} \mathrm{O}$ PROUNI concede bolsas de estudo em cursos de graduação em instituições privadas do ensino superior. 


\section{Considerações finais}

Os altos índices de desistência nos dois primeiros semestres do curso foram confirmados ao longo dos anos de pesquisa e mostraram-se compatíveis com as taxas de ingressantes que, apesar do sucesso escolar de terem conquistado uma vaga no ensino superior e mesmo antes das primeiras avaliações, declaravam a pretensão de não cursar a Licenciatura em Ciências.

Os elementos de vulnerabilidade acadêmica revelaram-se interligados entre si e compondo um sistema complexo que acaba influenciando de forma significativa a permanência ou a desistência do curso. Os laços afetivos, a orientação vocacional, a maturidade/imaturidade, a compreensão/incompreensão familiar sobre a universidade, a fragilidade da formação básica, a cultura de pouco estudo, o raciocínio baseado no senso comum sobre ciência (algo para "poucos e iluminados") e sobre docência ("precisa ter dom, é vocação"), a escassez de abordagens ativas e interdisciplinares para o ensino e a precarização das universidades federais, emergiram como elementos que permeiam a mente do estudante. A maior ou menor visibilidade e compreensão institucional desses problemas pode incentivar ou restringir o processo de saída dos alunos.

No entanto, a saída de alunos no primeiro ano do curso não se revelou fortemente vinculada ao insucesso escolar, a reprovações recorrentes ou ao abandono dos estudos, de acordo como conceito de evasão encontrado na literatura. Se levarmos em consideração as taxas expressivas de ingressantes oriundos de outras universidades, as taxas de ingressantes que declaram o desejo de não cursar, e compararmos com os desistentes no primeiro ano, teremos um quadro que se aproxima de um processo de mobilidade, com entradas e saídas, ao invés de um processo de evasão. A ausência de um registro eficiente e eficaz para acompanhar o aluno ao longo de sua trajetória na rede de ensino superior dificulta a observância dos elementos conceituais invariantes (HARDY-VALLÉE, 2013).

Por fim, agregamos a dúvida sobre a validade teórica de, no contexto de uma rede nacional permeada pela expansão, mobilidade e seleção unificada, analisar-se isoladamente a evasão de um curso. Mesmo se flexibilizarmos as fronteiras de evasão, a transferência do conceito, originalmente elaborado para referir-se à educação básica, universalizante e obrigatória, para o ensino superior, já significa uma alteração considerável de contexto educacional e, consequentemente, no âmbito do elemento invariante de um conceito (HARDY-VALLÉE, 2013). A diferença entre o dever estar na escola básica, expresso no processo que culminou com obrigatoriedade da educação dos 4 aos 17 anos, enquanto estratégia de universalização do ensino básico ${ }^{10}$ (BRASIL, 2009), e o direito ao ensino superior, expresso no livre arbítrio de escolha de um futuro profissional, insere uma significativa mudança no conceito, abrindo as portas para confundir-se evasão com mobilidade. Por outro lado, a saída prematura dos alunos, muitas vezes anunciada e planejada no bojo do sucesso escolar simbolizado pelo ingresso ao ensino superior e sem a presença das sucessivas reprovações ou da retenção no curso não permite verificar a relação, com fortes indícios de causalidade, entre insucesso escolar e evasão presente na origem da conceituação no ensino básico.

Desta forma, acreditamos que o uso do conceito de evasão para referir-se ao fenômeno de saída prematura de alunos do Curso Licenciatura em Ciências precisa ser problematizado

\footnotetext{
${ }^{10}$ Emenda constitucional no 59 de 11/11/2009.
} 
Rangel, F. O.; Stoco, S.; Silva, J. A.; Testoni, L. A.; Brockington, J. G. O., Cericato, I. L.

e revisto, uma vez que ele tem orientado ações institucionais baseadas nessas definições, com eficiência e eficácia questionáveis.

\section{Referências}

ALMEIDA, M. E. B. Inclusão digital do professor: formação e prática pedagógica. São Paulo: Ed. Articulação Universidade Escola, 2004.

ANDRÉ, M. E. D. A. O papel da pesquisa na formação e na prática dos professores. Campinas: Papirus, 2010.

BAGGI, C. A. S.; LOPES, D. A. Evasão e avaliação institucional no ensino superior: uma discussão bibliográfica. Avaliação: revista da avaliação da educação superior, Campinas, v. 16, n. 2, p. 355-374, 2011. DOI: https://doi.org/10.1590/S1414-40772011000200007.

BRASIL. Emenda constitucional n ${ }^{\circ}$ 59, de 11 de novembro de 2009. Brasília, 2009. Disponível em: http://www.planalto.gov.br/ccivil_03/Constituicao/Emendas/Emc/emc59. htm. Acesso em: 20 fev. 2019.

BRASIL. Ministério da Educação. Diplomação, retenção e evasão nos cursos de graduação em instituições de ensino superior públicas. Brasília, 1996. Disponível em: http://www.dominiopublico.gov.br/pesquisa/DetalheObraForm.do?select_action=\&co_ obra $=27010$. Acesso em: 25 maio 2016.

CARVALHO, G. S. Literacia científica: conceitos e dimensões. In: AZEVEDO, F; SARDINHA, M. G. (coord). Modelos e práticas em literacia. Lisboa: Lidel, 2009.

p. 179-194. Disponível em: http://repositorium.sdum.uminho.pt/handle/1822/9695. Acesso em: 20 fev. 2019.

CASTELS, M. A sociedade em rede. 9. ed. Rio de Janeiro: Paz e Terra, 2006.

COLAGRANDE, E. A.; RANGEL, F. O.; LEITE, L. O. C. Um olhar na licenciatura em ciências: investigando crenças dos professores em formação sobre natureza da ciência e relações CTSA. In: ENCONTRO NACIONAL DE PESQUISA EM EDUCAÇÃO EM CIÊNCIAS - ENPEC. Atas [...]. Águas de Lindóia, 2013. Disponível em: http://www.nutes. ufrj.br/abrapec/ixenpec/atas/resumos/R0394-1.pdf. Acesso em: 20 fev. 2019.

COSTA, A.; FERNANDES NETO, E.; SOUZA, G. A proletarização do professor. 2. ed. São Paulo: Instituto José Luís e Rosa Sundermann, 2009.

GATTI, B. A. et al. A atratividade da carreira docente no Brasil: relatório final. São Paulo: Fundação Carlos Chagas, 2009. Disponível em: http://www.zerohora.com.br/ pdf/15141177.pdf. Acesso em: 20 fev. 2019.

HARDY-VALLÉE, B. Que é um conceito? São Paulo: Parábola, 2013.

HOOD, C. The "new public management" in the 1980s: variations on a theme. Accounting, Organizations and Society, Kidlington, v. 20, n. 2-3, p. 93-109, 1995. DOI: https://doi. org/10.1016/0361-3682(93)E0001-W. 
Evasão ou mobilidade: conceito e realidade ...

INEP. Sinopses estatísticas da educação superior: graduação. Brasília, [2018]. Disponível em: http://inep.gov.br/sinopses-estatisticas-da-educacao-superior. Acesso em: 20 fev. 2019.

PATTTO, M. H. S. A produção do fracasso escolar: histórias de submissão e rebeldia. São Paulo: Casa do Psicólogo, 2000.

PIAGET, J. Para onde vai a educação? 16. ed. Rio de Janeiro: José Olympio, 2002.

PIMENTA, S. G.; FRANCO, M. A. S. Pesquisa em educação: possibilidades investigativas/formativas da pesquisa-ação: v. 1. São Paulo: Loyola, 2008.

PIMENTA, S. G.; FRANCO, M. A. S. Pesquisas em educação: possibilidades investigativas/formativas da pesquisa-ação: v. 2. 2. ed. São Paulo: Loyola, 2014.

RANGEL, F. O.; SILVA, J. A.; CARDOSO, C. R.; OLIVEIRA, E. N.; FERREIRA, A. V. T. S. Controvérsias no conceito de evasão de um curso de formação de professores de ciênciasfísica e a expansão do ensino superior federal. In: ENCONTRO DE PESQUISA EM ENSINO DE FÍSICA, 14., 2012, Maresias. Anais [...]. Maresias: EPEF, 2012. p. 1-9.

RANGEL, F. O.; CERICATO, I. L.; STOCO, S.; BROCKINGTON, J. G. O.; TESTONI, L. A.; SILVA, J. A. Evasão e vulnerabilidade acadêmica numa licenciatura em ciências. In: ENCONTRO NACIONAL DE PESQUISA EM EDUCAÇÃO EM CIÊNCIAS, 10., 2015, Águas de Lindóia. Anais [...]. Águas de Lindóia: ABRAPEC, 2015. p. 1-8.

REVISTA BRASILEIRA DE ESTUDOS PEDAGÓGICOS. Brasília, DF.: INEP, 20032017. ISSN: 0034-7183. Disponível em: http://rbep.inep.gov.br/index.php/rbep. Acesso em: 23 jul. 2018.

RIBEIRO, E.; HIGA, I. Evasão e permanência num curso de licenciatura em física. In: ENCONTRO NACIONAL DE PESQUISA EM EDUCAÇÃO EM CIÊNCIAS, 10., 2015, Águas de Lindoia. Anais [...]. Águas de Lindóia: ENPEC, 2015. Disponível em: http:// www.abrapecnet.org.br/enpec/x-enpec/anais2015/lista_area_17.htm. Acesso em: 20 fev. 2019.

RIBEIRO, S. C. A pedagogia da repetência. Estudos Avançados, São Paulo, v. 5, n. 12, p. 7-21, 1991. DOI: https://doi.org/10.1590/S0103-40141991000200002.

RISTOFF, D. Evasão: exclusão ou mobilidade. Florianópolis: UFSC, 1995 (MIMEO).

RUBBA, P. A.; HARKNESS, W. L. Examination of preservice and in-service secondary science teachers' beliefs about science-technology-society interactions. Science Education, Hoboken, v. 77, n. 4, p. 407-431, 1993. DOI: https://doi.org/10.1002/sce.3730770405.

SANTOS, M. A ubanização brasileira. São Paulo: Hucitec, 1996.

SANTOS, M. A.; ARABI, T. R. A.; CESPEDES, J. G. Evasão nos campi da UNIFESP.

São José dos Campos: UNIFESP, 2015. Disponível em: https://www.unifesp.br/ reitoria/prograd/pro-reitoria-de-graduacao/informacoes-institucionais/graduacao-emnumeros?download=534:estudo-evasao-unifesp. Acesso em: 20 fev. 2019. 
Rangel, F. O.; Stoco, S.; Silva, J. A.; Testoni, L. A.; Brockington, J. G. O., Cericato, I. L.

SANTOS, M. E. N. V. M. Encruzilhadas de mudança no limiar do século XXI: coconstrução do saber científico e da cidadania via ensino CTS de ciências. In: ENCONTRO NACIONAL DE PESQUISA EM EDUCAÇÃO EM CIÊNCIAS, 2., 1999, Valinhos. Anais [...]. Valinhos: ABRAPEC, 1999.

SILVA FILHO, R. L. L.; MOTEJUNAS, P. R.; HIPÓLITO, O.; LOBO, M. B. C. M. A evasão no ensino superior brasileiro. Cadernos de Pesquisa, São Paulo, v. 37, n. 132, p. 641-659, 2007. Disponível em: http://www.scielo.br/pdf/cp/v37n132/a0737132.pdf. Acesso em: 20 fev. 2019.

THIOLLENT, M. Metodologia da pesquisa-ação. 11. ed. São Paulo: Cortez, 2002.

UNIVERSIDADE FEDERAL DE SÃO PAULO. Análise do perfil de estudantes ingressantes da Universidade Federal de São Paulo. São Paulo, 2016. Disponível em: http://www.unifesp.br/reitoria/prograd/pro-reitoria-de-graduacao/informacoesinstitucionais/todos-os-arquivos/category/7-perfil-socio-economico-ingressantes. Acesso em: 20 fev. 2019.

UNIVERSIDADE FEDERAL DE SÃO PAULO. Projeto pedagógico do curso de ciências. São Paulo: UNIFESP, 2013. Disponível em: http:/ /www3.unifesp.br/prograd/ app/cursos/index.php/prograd/arq_projeto/1225. Acesso em: 15 jul. 2017.

VALENTE, J. A. Mudanças na sociedade, mudanças na educação: o fazer e o compreender. In: VALENTE, J. A. (org.). O computador na sociedade do conhecimento. Campinas: Unicamp: Núcleo de Informática Aplicada à Educação, 1999. p. 29-48.

Artigo recebido em 09/08/2017. Aceito em 16/09/2018.

Contato: Av. Conselheiro Rodrigues Alves, 391, ap. 31, Vila Mariana, São Paulo, SP, CEP 04014-011, Brasil. 